Gut, 1971, 12, 449-451

\title{
A trial of deglycyrrhizinated liquorice in the treatment of duodenal ulcer
}

\author{
H. FELDMAN AND T. GILAT \\ From the Departments of Gastroenterology and Internal Medicine B, Ichilov Hospital, Tel-Aviv University \\ Medical School, Tel-Aviv, Israel
}

SUMMARY A double-blind trial of deglycyrrhizinated liquorice was performed in 47 patients with active duodenal ulcer. Twenty-four patients received a placebo and 23 the trial medication (CavedS) for one month. Both groups were clinically similar. No advantage of deglycyrrhizinated liquorice over placebo was found.

The introduction of liquorice extract and its active principle carbenoxolone and subsequent evidence of their efficacy in the treatment of gastric ulcers marked a significant advance in ulcer therapy (Doll, Hill, Hutton, and Underwood, 1962; Doll, Hill, and Hutton, 1965; Horwich and Galloway, 1965; Turpie and Thomson, 1965; Bank, Marks, Palmer, Groll, and van Eldik, 1967). This is a new class of drugs devoid of antacid activity which possibly enhance mucosal resistance. To avoid the sodium and fluid retention caused by whole liquorice extract and carbenoxolone, the latter was eliminated and a new preparation, deglycyrrhizinated liquorice (Caved-S) introduced. It did not cause sodium or fluid retention and was reported to be active in gastric ulcer (Tewari and Trembalowicz, 1968; Russell and Dickie, 1968), and more interestingly in duodenal ulcer in which carbenoxolone was not proved to be effective (Doll et al, 1962; Cliff and Milton-Thompson, 1970). In this article we report a double-blind trial of deReceived for publication 23 March 1971. glycyrrhizinated liquorice (Caved-S) in patients with duodenal ulcer.

\section{Material and Methods}

Included in the trial were patients from the clinic suffering from duodenal ulcer for at least six months. The patients had recent radiological proof of a deformed bulb or ulcer niche and had ulcer pains at the start of the study. Data on the subjects studied are given in Table I. The following tests were performed before and after the trial: blood count, urineanalysis, blood urea, GO-transaminase, bicarbonate, sodium, potassium, and chloride. Patients were seen before and then one week, two weeks, and 30 days after the start of therapy. At each visit they were examined, interviewed, and the symptoms recorded using a standard questionnaire. Blood pressure and weight were also recorded. We personally examined and followed up all patients.

The study was double blind with patients receiving

\begin{tabular}{lcc}
\hline & Placebo Group (24) & Treated Group (23) \\
\hline Age & & \\
Mean (range) & $43 \cdot 4(15-64)$ & $38 \cdot 9$ (19-70) \\
Sex & 17 & 15 \\
Male & 7 & 8 \\
Female & $10 \cdot 1$ & $8 \cdot 2$ \\
Average duration of disease (yr) & 3 & 3 \\
Previous complications (bleeding, perforation) & 10 & 11 \\
Previous admissions to hospital & 18 & 13 \\
No. of subjects & 12 & 14 \\
No. of admissions & $2 \cdot 5$ & $2 \cdot 6$ \\
Smokers & 10 & 12 \\
Average duration of present attack (mth) & 1 & 2 \\
No. of subjects with attacks $=1$ month & & \\
Eliminated from study & & \\
\hline
\end{tabular}

Table I Patients studied 
coded tablets, the code being revealed only after completion of the study. Patients received two tablets three times a day after meals for $\mathbf{3 0}$ days and were instructed to chew them before swallowing. Each Caved-S tablet contained $380 \mathrm{mg}$ deglycyrrhizinated powdered block liquorice, $100 \mathrm{mg}$ bismuth subnitrate, $100 \mathrm{mg}$ aluminium hydroxide gel, $200 \mathrm{mg}$ magnesii carbonas levis, $100 \mathrm{mg}$ sodium bicarbonate, and $30 \mathrm{mg}$ powdered frangula bark. The placebo tablets were inert tablets of the same composition except that each contained lactose flavored with aniseed to simulate the taste of liquorice.

Patients were instructed to eat at least five meals a day and to take an antacid tablet as necessary for pain or heartburn and to record the number of tablets taken. The antacid (Lucol) contained $180 \mathrm{mg}$ aluminium hydroxide and $60 \mathrm{mg}$ magnesium hydroxide. No dietary restrictions were imposed. Fifty patients started the trial and 47 completed it. One patient developed pyloric stenosis after nine days of treatment and was operated on; another patient failed to appear for follow up. Both these patients belonged to the treated group. A patient of the placebo group stopped taking the coded tablets and changed medication during the trial period. Results of the trial were evaluated before revealing the code. The disappearance of pain during the trial was classified as a success while the persistence of pain was classified as a failure.

\section{Results}

Results of treatment are detailed in Table II. There were no significant differences between the two groups. There were no side effects attributable to treatment and, in particular, no fluid retention and no effects on blood pressure and electrolytes. Laboratory examinations remained normal through- out the study. Constipation was improved during treatment in both groups.

\section{Discussion}

Gassman and Forster (1963) reported on the favourable effects of deglycrryhizinated liquorice in patients with duodenal ulcer. Of 30 patients studied 'good' results were obtained in 17 and an 'improved effect' noted in another eight. 'All postprandial complaints completely disappeared within five to eight days after the use of an average of $\mathbf{4 0}$ tablets' in these patients as well as in some patients with gastric ulcer. No controls were studied and the trial was not blind. Russell and Dickie (1968) reported results of a double-blind trial in 16 patients with gastric ulcer and 32 patients with duodenal ulcer. An effect was noted in the gastric ulcer patients, while in duodenal ulcer patients the difference in the clinical improvement between the treated group and the control group 'was not statistically significant'.

Tewari and Trembalowicz (1968) reported excellent results in $\mathbf{4 8}$ patients with duodenal ulcer and in six patients with gastric ulcer in a double-blind trial. The clinical effect is reported for both ulcer types together. Results were 'good' or 'improved' in 25 of 28 treated patients versus eight of 26 controls. In 15 patients with duodenal ulcer the therapy was crossed over after four weeks and again much better results were reported in the treated group with 12 out of 15 'improved' versus three out of 15 controls. Mills and Damrau (1969) report a double-blind crossover trial including 22 patients with duodenal ulcer. The patients were treated for four weeks with a crossover at two weeks. Only 18 of the 22 patients had pain at the start of the trial. Relief of pain was obtained in $78 \%$ of treated patients and in $33 \%$ of the placebo group.

\begin{tabular}{|c|c|c|c|}
\hline Symptom & No. with Symptoms & Symptom Relieved & Average Time to Relief (dy) \\
\hline $\begin{array}{l}\text { Pain } \\
\text { Placebo } \\
\text { Caved-S }\end{array}$ & $\begin{array}{l}24 \\
23\end{array}$ & $\begin{array}{l}11 \\
12\end{array}$ & $\begin{array}{l}15.2 \\
18.8\end{array}$ \\
\hline $\begin{array}{l}\text { Nocturnal pain } \\
\text { Placebo } \\
\text { Caved-S }\end{array}$ & $\begin{array}{l}21 \\
21\end{array}$ & $\begin{array}{l}14 \\
16\end{array}$ & $\begin{array}{l}13.4 \\
15.9\end{array}$ \\
\hline $\begin{array}{l}\text { Heartburn } \\
\text { Placebo } \\
\text { Caved-S }\end{array}$ & $\begin{array}{l}19 \\
16\end{array}$ & $\begin{array}{l}9 \\
7\end{array}$ & $\begin{array}{l}14.7 \\
19.0\end{array}$ \\
\hline $\begin{array}{l}\text { Nausea } \\
\text { Placebo } \\
\text { Caved-S }\end{array}$ & $\begin{array}{l}14 \\
14\end{array}$ & $\begin{array}{l}9 \\
9\end{array}$ & $\begin{array}{l}15.7 \\
12.8\end{array}$ \\
\hline $\begin{array}{l}\text { Vomiting } \\
\text { Placebo } \\
\text { Caved-S }\end{array}$ & $\begin{array}{l}5 \\
6\end{array}$ & $\begin{array}{l}2 \\
4\end{array}$ & $\begin{array}{r}7 \cdot 0 \\
15.5\end{array}$ \\
\hline
\end{tabular}

Table II Results ${ }^{1}$

${ }^{1}$ The average consumption of antacid tablets in 30 days was 107 in the placebo group and 91 in the treated group. 
In our study no significant differences were found between the placebo and the treated groups.

The differences between the reported results are not easy to explain. Crossover trials in patients with duodenal ulcer are not easy to evaluate. In particular, it is not clear how after one month of reportedly successful therapy with complete relief of symptoms another drug (placebo) can be evaluated using clinical criteria. Even if the placebo is used first, the attack may be expected to subside within a month in part of the group.

In view of the conflicting reports more studies will have to be performed before a therapeutic effect can be attributed to deglycyrrhizinated liquorice in patients with duodenal ulcer.

It is not clear whether our results reflect on the efficacy of liquorice extract after the removal of carbenoxolone or merely on its efficacy in duodenal as contrasted to gastric ulcer. In common with others we found no side effects attributable to treatment with deglycyrrhizinated liquorice.

We thank Cedona of Haarlem, The Netherlands, for the supply of Caved-S tablets.

\section{References}

Bank, S., Marks, I. N., Palmer, P. E. S., Groll, A., and Eldik, E. van. (1967). A trial of carbenoxolone sodium in the treatment of gastric ulceration. S. Afr. Med. J., 41, 297-300.

Cliff, J. M., and Milton-Thompson, G. J. (1970). A double-blind trial of carbenoxolone sodium capsules in the treatment of duodenal ulcer. Gut, 11, 167-170.

Doll, R., Hill, I. D., and Hutton, C. G. (1965). Treatment of gastric ulcer with carbenoxolone sodium and oestrogens. Gut, 6, 19-24.

Doll, R., Hill, I. D., Hutton, C. F., and Underwood, D. J., II. (1962). Clinical trial of a triterpenoid liquorice compound in gastric and duodenal ulcer. Lancet, 2, 793-796.

Gassmann, R., and Forster, G. (1963). Erfahrungen mit dem Succus liquiritiae-prăparat Caved-S bei der Behandlung von Ulzern des Magen-Darm-Tractes. Ther. Umsch., 20, 306-312.

Horwich, L., and Galloway, R. (1965). Treatment of gastric ulceration with carbenoxolone sodium: clinical and radiological evaluation. Brit. med. J., 2, 1274-1277.

Mills, D. H., and Damrau, F. (1969). Deglycyrrhizinized glycyrrhiza in treatment of peptic ulcer; double-blind crossover clinical trial in $\mathbf{4 0}$ cases. Int. med. Dig., 4, 36-44.

Russell, R. I., and Dickie, J. E. N. (1968). Clinical trial of a deglycyrrhizinised liquorice preparation in peptic ulcer. J. Ther. clin. Res., 2 (1), 2-5.

Tewari, S. N., and Trembalowicz, F. C. (1968). Some experience witk deglycyrrhizinated liquorice in the treatment of gastric and duodenal ulcers with special reference to its spasmolytic effect. Gut, 9, 48-51.

Turpie, A. G. G., and Thomson, T. J. (1965). Carbenoxolone sodiun. in the treatment of gastric ulcer with special reference to sideeffects. Gut, 6, 591-594. 